\title{
Estimating the influence of life satisfaction and positive affect on later income using sibling fixed effects
}

\author{
Jan-Emmanuel De Neve ${ }^{a, b, 1}$ and Andrew J. Oswald ${ }^{c, d}$ \\ ${ }^{a}$ School of Public Policy, University College London, London WC1H 9QU, United Kingdom; ${ }^{b}$ Centre for Economic Performance, London School of Economics, \\ London WC2A 2AE, United Kingdom; 'Department of Economics and Centre for Competitive Advantage in the Global Economy, University of Warwick, \\ Coventry CV4 7AL, United Kingdom; and dinstitute for the Study of Labor, D-53113 Bonn, Germany
}

Edited by Jose A. Scheinkman, Princeton University, Princeton, NJ, and approved October 15, 2012 (received for review July 10, 2012)

The question of whether there is a connection between income and psychological well-being is a long-studied issue across the social, psychological, and behavioral sciences. Much research has found that richer people tend to be happier. However, relatively little attention has been paid to whether happier individuals perform better financially in the first place. This possibility of reverse causality is arguably understudied. Using data from a large US representative panel, we show that adolescents and young adults who report higher life satisfaction or positive affect grow up to earn significantly higher levels of income later in life. We focus on earnings approximately one decade after the person's well-being is measured; we exploit the availability of sibling clusters to introduce family fixed effects; we account for the human capacity to imagine later socioeconomic outcomes and to anticipate the resulting feelings in current well-being. The study's results are robust to the inclusion of controls such as education, intelligence quotient, physical health, height, self-esteem, and later happiness. We consider how psychological well-being may influence income. SobelGoodman mediation tests reveal direct and indirect effects that carry the influence from happiness to income. Significant mediating pathways include a higher probability of obtaining a college degree, getting hired and promoted, having higher degrees of optimism and extraversion, and less neuroticism.

subjective well-being | personal earnings

$T^{\mathrm{s}}$ he relationship between money and human happiness has generated a burgeoning cross-disciplinary literature. Virtually all published research on this matter has considered the effects of income upon subjective well-being (e.g., refs. 1-9). This study examines - and provides evidence of - the reverse. By using longitudinal information within families (exploiting so-called sibling fixed effects), it finds that happier people go on, many years later, to earn greater incomes. The results are suggestive of some form of causal relationship between well-being and income.

That the scholarly debate has mostly developed unidirectionally should probably not come as a surprise, given that it mirrors both our societal preoccupation with economic development and the conventional wisdom that human well-being follows from high income. The question of whether "money buys happiness" has not only dominated the investigation into the relationship between money and happiness, it has also taken on increasingly causal language because research showed positive (but marginally diminishing) effects of rising income on well-being, with some differences observed between life satisfaction and emotional wellbeing (1). However, relatively little attention has been paid to whether happier individuals perform better financially in the first place. This possibility of reverse causality is arguably understudied.

In this study, we therefore address the question of whether "happiness pays." We do so in a US representative panel of $>10,000$ individuals and explore the potential mediating pathways running from happiness to later income. This work does not intend to undermine the aforementioned literature on the effect of income on well-being. Rather, the goal is to make the case that the relationship between income and happiness is dynamic and that effects may run in both directions, thus complementing existing scholarship.

An effect running from subjective well-being to income could exist for a number of reasons. Happiness has various correlates such as health (10), social networks (11), and self-esteem (12) that, in turn, are known to positively influence labor market outcomes and that may thus play a mediating role. More recent neuroscientific research provides clues that greater subjective well-being is associated with particular neurological variation, which, in turn, is associated with improved cognitive skills and economic outcomes. Such neurological mediation pathways center on the role of positive emotions (reward) in stimulating the dopaminergic system and increasing cognitive capacity for memory tasks and attention span (13-16). These neuroscientific insights and aforementioned correlates provide some reason to believe that there could be an effect running from subjective well-being to economic outcomes.

A handful of studies have tried to estimate the influence of subjective well-being on later income. Diener et al. (17) found a positive correlation between "cheerfulness" measured in a sample of elite college students and their income levels some $19 \mathrm{y}$ later. This association is particularly significant for those with below average levels of cheerfulness. Diener and colleagues later expanded on this finding to show that individuals who experience the highest levels of happiness do not necessarily perform best in terms of later income and that the "optimal" level of happiness for later income appears to be a moderately high level of happiness (18). Three other studies considered the broader effects of happiness on life events, including income, marriage, employment, and health $(19,20)$, as well as consumption and savings behavior (21). The panels used in these studies are the British Household Panel Study, Russia Longitudinal Monitoring Survey, German Socio-Economic Panel, and the De Nederlandsche Bank Household Survey in the Netherlands. In a laboratory setting, Oswald et al. (22) induced variation in positive mood and found that it is predictive of productivity in a laboratory task. The promising results from inquiries into the socioeconomic and productivity effects of happiness have led some to speak of a "happiness advantage" (23) in shaping career success (24) and provide further ground for why a deeper investigation is warranted.

Although the aforementioned studies are important because they point toward a potential role for happiness in shaping socioeconomic outcomes, they face a number of methodological difficulties. First, these studies continue to leave room for

\footnotetext{
Author contributions: J.-E.D.N. and A.J.O. designed research; J.-E.D.N. performed research; J.-E.D.N. analyzed data; and J.-E.D.N. and A.J.O. wrote the paper.

The authors declare no conflict of interest.

This article is a PNAS Direct Submission.

${ }^{1}$ To whom correspondence should be addressed. E-mail: jdeneve@post.harvard.edu.
}

This article contains supporting information online at www.pnas.org/lookup/suppl/doi:10. 1073/pnas.1211437109/-/DCSupplemental. 
alternative explanations: Cross-sectional results may be the result of genetic confounding and other omitted variables; longitudinal designs have so far not accounted for the human capacity to imagine later socioeconomic outcomes and anticipate the resulting feelings in current well-being $(25,26)$; and experimental designs are not in a position to evaluate longer-term effects outside the laboratory.

Second, previous work has separately considered measures of mood, happiness, life satisfaction, and mental health. The more recent literature, however, has argued that emotional well-being and satisfaction with life are two important yet different components of well-being (1). Emotional well-being refers to the frequency and intensity of everyday emotional experiences (both positive and negative). The positive emotions and the experience of feeling happy are commonly referred to as "positive affect." Life satisfaction, conversely, refers to a longer-term evaluation of one's life. Although measures of positive affect and life satisfaction correlate- and load onto a common genetic factor (27) they show varying salience in different circumstances of people's lives, including in their relationship to income and age $(1,28,29)$. None of the previous studies considered the dual effect of emotional well-being and life satisfaction on later income, even though Kahneman and Deaton (1) conclude that the effect of income on positive affect is less pronounced (and ceases beyond an annual income of $\sim \$ 75,000)$ compared with the effect of income on life satisfaction. It is therefore necessary to investigate whether a similar distinction can be made in the opposite direction, i.e., the effect running from well-being on income.

Finally, if income is indeed endogenous to happiness, it becomes important to study how happiness may influence income. To address these questions, this work studies whether life satisfaction and positive affect are predictive of later incomewhile tackling the endogeneity concerns that were hitherto unaddressed-and investigates potential mediating pathways.

\section{Results}

Fig. 1 illustrates the study's key result. It plots the (uncorrected) relationship between subjective well-being and later earnings in a large US representative panel study (Add Health). Reports of positive affect or life satisfaction in adolescence and young adulthood correlate significantly with income around age 29 (all between $r=0.078$ and 0.090 , with $P<0.001$; Table S1). Income here is defined in the following way: "Now think about your personal earnings. In $\{2006 / 2007 / 2008\}$, how much income did you receive from personal earnings before taxes, that is, wages or salaries, including tips, bonuses, and overtime pay, and income from self-employment?" Similar to the findings on "cheerfulness" by Diener et al. (17), we observed that the relationship is particularly pronounced for those individuals with lower levels of happiness. In fact, reporting a profoundly unhappy adolescence is associated with an income around age 29 that is $~ 30 \%$ less than average, whereas a very happy adolescence is associated with a later income that is $\sim 10 \%$ above average.

Regression analyses reported in Table 1 confirm this pattern. The predictive power of happiness on later earnings depends on the lag time between both variables; e.g., a 1 SD increase in life satisfaction at the age of 22 is associated with a $5 \%$ increase in earnings at the age of $29(\mathrm{SD}=0.81$ on a scale of 5$)$. In absolute terms, a 1-point increase in life satisfaction at the age of 22 is associated with almost $\$ 2,000$ higher earnings at the age of 29 (this dollar value is obtained in an empirical model identical to the one reported in Table 1 except for using income values instead of their natural logarithm).

The analyses reported here include the following covariants: age, sex, ethnicity, education, intelligence quotient (IQ), physical health, height, and self-esteem (for a detailed specification of these variables, see Table S2). Most of these covariates are standard. However, unlike previous longitudinal studies of the effect of subjective well-being on later socioeconomic outcomes and life events (17-21), the richness of the dataset used here allows us to incorporate a measure of self-esteem that is surveyed at the same time as positive affect and life satisfaction. Self-esteem is a psychological construct distinct from happiness (12) and is an important driver of labor market outcomes (30). As such, it is an important variable to control for in a study of the effect of happiness on later outcomes because not doing so may otherwise bias the coefficients obtained on happiness (results in Table 2 indicate that self-esteem and subjective well-being have similarly significant effects on later earnings). Furthermore, introducing a measure of self-esteem may allow us to control for feelings that anticipate happiness related to individual expectations of socioeconomic outcomes. The human capacity to imagine later outcomes and anticipate the resulting feelings in current well-being is well-known $(25,26)$. Self-esteem may capture the confidence one has in later earnings potential and thus also account for the positive or negative feelings associated with the anticipated outcomes. Although longitudinal studies allow for measuring subjective well-being before the outcome of interest, they cannot prevent expectations about those later outcomes from being correlated with an earlier state of mind and thus introduce bias into the earlier measures of happiness. Introducing a concurrent measure of self-esteem alongside subjective well-being in adolescence and young adulthood may therefore also help account for anticipated feelings surrounding earnings potential.

Subjective well-being has an important latent or stable component that is considered to be contingent on genetic variation and certain personality traits $(27,31-34)$. To help distinguish variation in positive affect and life satisfaction-in adolescence and young adulthood-from variation in innate predispositions we also include in our analyses a measure of positive affect that is reported at the same time as income (around age 29). Doing so is important because it allows us to capture the influence of variation in subjective well-being beyond the latent dimensions specific to the individual.

Looking at models 1-3 in Table 1, we find that positive affect in 1994 (age 16) and 1996 (age 18), as well as life satisfaction in 2001 (age 22), each significantly predict later earnings (age 29). Model 4 jointly considers all these measures of subjective wellbeing over time and shows that the predictive power of variation in happiness on later income at those time points gradually rises as the time lag shrinks.

The analyses reported in Table 2 go one step further. They exploit the availability of sibling clusters in the data to introduce family fixed effects (for those individuals identified as twin pairs, full-siblings, half-siblings, or unrelated siblings raised together). The siblings' sample is similar in demographic composition to the full Add Health sample (35). The structure of these data allows us to compare siblings to each other while holding the family environment constant (as well as a substantial portion of the genetic variation in most cases), which, in turn, aids our interpretation of the relationship between well-being and income.

Table 2 shows that a 1 SD difference in life satisfaction compared with the family mean at age 22 is associated with a $6 \%$ difference in earnings compared with the family mean at age 29. In absolute terms, a 1-point difference in life satisfaction (on a scale of 5) compared with the family mean at age 22 is associated with an almost $\$ 4,000$ difference in earnings compared with the family mean at age 29 (this dollar value is obtained in an empirical model identical to the one reported in Table 2, except for using income values instead of their natural logarithm). Looking at models 1-3 in Table 2, we find that measures of positive affect and life satisfaction in adolescence and early adulthood are positively associated with later earnings. Sibling fixed-effects model predicted values are plotted in Figs. S1-S2. Model 4 jointly considers all these measures of subjective well-being over time and obtains a significant coefficient for life satisfaction on later 


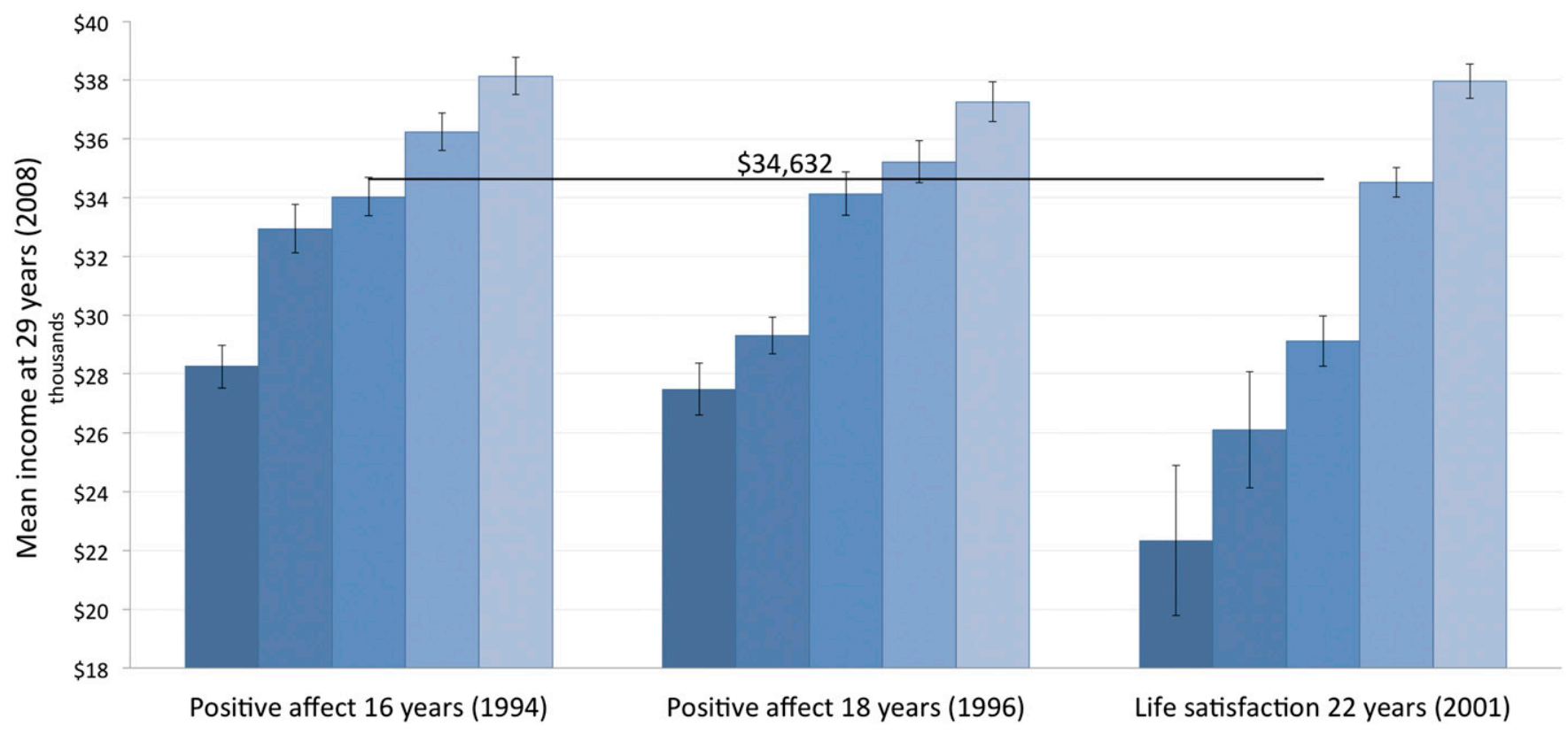

Fig. 1. The longitudinal relationship between subjective well-being (at ages 16,18 , and 22) and later earnings (at age 29). Response categories for positive affect (at ages 16 and 18) and life satisfaction (at age 22) are presented in relationship with their respective mean income levels at about age 29. Mean income across the sample is $\$ 34,632$ at age 29 . $N=14,867$ for positive affect at age $16, N=11,253$ for positive affect at age 18 , and $N=12,415$ for life satisfaction at age 22. The original positive affect variable categories are reshaped to a 5-point scale for ease of comparison. Error bars (2 SEs) are shown.

income. The effect sizes of the well-being measures remain relatively stable between Table 1 (full panel) and Table 2 (sibling panel). The lower significance levels in Table 2 are presumably due to the reduced number of observations in the sibling panel as well as having accounted for family fixed effects.

Tables S7 and S8 present results for an individual fixed-effects model and a Granger causality analysis that use the available information on earnings in 2001 (age 22). Both model specifications obtain highly significant results for the effect of lagged subjective well-being on earnings. However, we do not lend these results full credence, given that earnings at age 22 may not yet accurately represent individual income and also because these panel data allow for only one time interval, and the exogeneity assumption necessary for panel data models is unlikely to be satisfied.

If income is indeed endogenous to happiness, it becomes important to study how happiness comes to influence a person's income. Table 3 presents results for our investigation into potential mediating pathways. These univariate Sobel-Goodman

Table 1. Earnings equations: Linear regression models of log income at age 29 (2008) on lagged subjective well-being and covariates

\begin{tabular}{|c|c|c|c|c|c|c|c|c|}
\hline \multirow[b]{2}{*}{ Independent variable } & \multicolumn{2}{|c|}{ Model 1} & \multicolumn{2}{|c|}{ Model 2} & \multicolumn{2}{|c|}{ Model 3} & \multicolumn{2}{|c|}{ Model 4} \\
\hline & Coeff. & $P$ value & Coeff. & $P$ value & Coeff. & $P$ value & Coeff. & $P$ value \\
\hline Positive affect (1994) & 0.033 & 0.002 & & & & & 0.014 & 0.314 \\
\hline Positive affect (1996) & & & 0.044 & 0.000 & & & 0.030 & 0.037 \\
\hline Life satisfaction (2001) & & & & & 0.051 & 0.000 & 0.047 & 0.000 \\
\hline Positive affect (2008) & 0.092 & 0.000 & 0.089 & 0.000 & 0.086 & 0.000 & 0.074 & 0.000 \\
\hline Male & 0.149 & 0.000 & 0.146 & 0.000 & 0.147 & 0.000 & 0.145 & 0.000 \\
\hline Age & 0.089 & 0.000 & 0.084 & 0.000 & 0.088 & 0.000 & 0.085 & 0.000 \\
\hline College & 0.210 & 0.000 & 0.216 & 0.000 & 0.212 & 0.000 & 0.201 & 0.000 \\
\hline IQ & 0.038 & 0.001 & 0.037 & 0.004 & 0.043 & 0.000 & 0.030 & 0.022 \\
\hline Medication & 0.013 & 0.174 & 0.013 & 0.253 & 0.013 & 0.197 & 0.014 & 0.211 \\
\hline Height & 0.036 & 0.008 & 0.039 & 0.011 & 0.035 & 0.011 & 0.037 & 0.016 \\
\hline Self-esteem (1994) & 0.057 & 0.000 & & & & & 0.041 & 0.003 \\
\hline Self-esteem (1996) & & & 0.044 & 0.001 & & & 0.015 & 0.306 \\
\hline Self-esteem (2001) & & & & & 0.054 & 0.000 & 0.030 & 0.017 \\
\hline Black & -0.068 & 0.000 & -0.064 & 0.000 & -0.063 & 0.000 & -0.065 & 0.000 \\
\hline Hispanic & 0.056 & 0.000 & 0.065 & 0.000 & 0.051 & 0.000 & 0.064 & 0.000 \\
\hline Asian & 0.062 & 0.000 & 0.063 & 0.000 & 0.061 & 0.010 & 0.064 & 0.000 \\
\hline Intercept & 10.15 & 0.000 & 10.14 & 0.000 & 10.15 & 0.000 & 10.14 & 0.000 \\
\hline$N$ & \multicolumn{2}{|c|}{11,080} & \multicolumn{2}{|c|}{8,620} & \multicolumn{2}{|c|}{11,086} & \multicolumn{2}{|c|}{8,585} \\
\hline$R^{2}$ & \multicolumn{2}{|c|}{0.12} & \multicolumn{2}{|c|}{0.12} & \multicolumn{2}{|c|}{0.13} & \multicolumn{2}{|c|}{0.13} \\
\hline
\end{tabular}

Variable coefficients (Coeff.) are standardized, and $P$ values are presented. Variable definitions are in Table S2. 
Table 2. Earnings equations: Sibling fixed-effects models of log income at age 29 (2008) on lagged subjective well-being and covariates

\begin{tabular}{|c|c|c|c|c|c|c|c|c|}
\hline \multirow[b]{2}{*}{ Independent variable } & \multicolumn{2}{|c|}{ Model 1} & \multicolumn{2}{|c|}{ Model 2} & \multicolumn{2}{|c|}{ Model 3} & \multicolumn{2}{|c|}{ Model 4} \\
\hline & Coeff. & $P$ value & Coeff. & $P$ value & Coeff. & $P$ value & Coeff. & $P$ value \\
\hline Positive affect (1994) & 0.060 & 0.044 & & & & & 0.018 & 0.575 \\
\hline Positive affect (1996) & & & 0.048 & 0.110 & & & 0.035 & 0.264 \\
\hline Life satisfaction (2001) & & & & & 0.062 & 0.026 & 0.069 & 0.015 \\
\hline Positive affect (2008) & 0.071 & 0.010 & 0.062 & 0.028 & 0.066 & 0.016 & 0.043 & 0.132 \\
\hline Male & 0.119 & 0.007 & 0.135 & 0.003 & 0.114 & 0.009 & 0.134 & 0.003 \\
\hline Age & 0.129 & 0.000 & 0.115 & 0.000 & 0.127 & 0.000 & 0.115 & 0.000 \\
\hline College & 0.166 & 0.000 & 0.176 & 0.000 & 0.158 & 0.643 & 0.162 & 0.000 \\
\hline IQ & 0.003 & 0.960 & 0.018 & 0.660 & 0.022 & 0.573 & 0.017 & 0.685 \\
\hline Medication & -0.008 & 0.772 & -0.015 & 0.582 & -0.08 & 0.753 & -0.015 & 0.586 \\
\hline Height & 0.081 & 0.082 & 0.081 & 0.082 & 0.093 & 0.042 & -0.080 & 0.087 \\
\hline Self-esteem (1994) & 0.033 & 0.271 & & & & & 0.011 & 0.737 \\
\hline Self-esteem (1996) & & & 0.035 & 0.244 & & & 0.016 & 0.610 \\
\hline Self-esteem (2001) & & & & & 0.061 & 0.042 & 0.039 & 0.179 \\
\hline Intercept & 10.14 & 0.000 & 10.14 & 0.000 & 10.13 & 0.000 & 9.981 & 0.000 \\
\hline$N$ & \multicolumn{2}{|c|}{3,216} & \multicolumn{2}{|c|}{3,029} & \multicolumn{2}{|c|}{3,217} & \multicolumn{2}{|c|}{3,017} \\
\hline$R^{2}$ & \multicolumn{2}{|c|}{0.11} & \multicolumn{2}{|c|}{0.13} & \multicolumn{2}{|c|}{0.11} & \multicolumn{2}{|c|}{0.13} \\
\hline
\end{tabular}

Variable coefficients are standardized, and $P$ values are presented. Variable definitions are in Table S2.

mediation tests consider potentially mediating variables that may carry some of the effect from happiness onto income (36). We chose a number of standard socioeconomic variables, as well as psychological constructs such as personality traits, optimism, and self-esteem. Only measures in 2008 are used-to reduce confounding with the earlier measures of subjective well-being. Table 3 shows that most of the chosen variables are correlated with earlier measures of positive affect and life satisfaction and also carry some part of their influence onto income. The most significant mediating pathways include obtaining a college degree, getting hired and promoted, higher degrees of optimism and extraversion, and less neuroticism. These variables each partially mediate the observed association with income and may represent an indirect effect as large as $\sim 38 \%$ in the case of positive affect (around age 18) and obtaining a college degree. These results provide support for causal mechanisms running from subjective well-being to later income. Table S9 presents the results for a multivariate mediation analysis that considers these mediating variables jointly. The total mediated effect for these variables is estimated to be between $68 \%$ and $78 \%$, thus revealing an important combined indirect effect, in addition to a direct effect, that carries the influence from happiness to income. These results suggest a relationship that is pleiotropic in nature, with psychological well-being having an independent effect on both income and the mediating variables.

\section{Discussion}

This study reverses one of the famous questions of social science. It is an attempt to explore the influence not of income upon well-being but instead of well-being upon income. As Fig. 1 illustrates, the linkages are estimated to be long and the empirical consequences large.

Table 3. Univariate Sobel-Goodman mediation tests on log income at age 29 (2008)

\begin{tabular}{|c|c|c|c|c|c|c|c|c|c|}
\hline \multirow{3}{*}{$\begin{array}{l}\text { Mediating } \\
\text { variable (data } \\
\text { are from 2008) }\end{array}$} & \multicolumn{9}{|c|}{ Independent variable } \\
\hline & \multicolumn{3}{|c|}{ Positive affect (1994) } & \multicolumn{3}{|c|}{ Positive affect (1996) } & \multicolumn{3}{|c|}{ Life satisfaction (2001) } \\
\hline & Coeff. & $P$ value & $\%$ & Coeff. & $P$ value & $\%$ & Coeff. & $P$ value & $\%$ \\
\hline Job & 0.017 & 0.000 & 15 & 0.025 & 0.000 & 22 & 0.019 & 0.000 & 18 \\
\hline Supervision & 0.006 & 0.000 & 5 & 0.006 & 0.000 & 5 & 0.006 & 0.000 & 6 \\
\hline College & 0.039 & 0.000 & 36 & 0.043 & 0.000 & 38 & 0.032 & 0.000 & 28 \\
\hline Married & 0.004 & 0.000 & 4 & 0.004 & 0.000 & 4 & 0.014 & 0.000 & 12 \\
\hline Optimism & 0.032 & 0.000 & 29 & 0.036 & 0.000 & 32 & 0.029 & 0.000 & 25 \\
\hline Self-esteem & 0.017 & 0.000 & 15 & 0.018 & 0.000 & 16 & 0.005 & 0.000 & 4 \\
\hline Openness & 0.004 & 0.003 & 4 & 0.005 & 0.010 & 4 & -0.000 & 0.651 & 0 \\
\hline Conscientiousness & 0.003 & 0.000 & 3 & 0.003 & 0.000 & 3 & 0.004 & 0.000 & 3 \\
\hline Extraversion & 0.006 & 0.000 & 5 & 0.006 & 0.000 & 5 & 0.004 & 0.000 & 4 \\
\hline Agreeableness & -0.001 & 0.181 & -1 & -0.002 & 0.126 & -2 & -0.000 & 0.672 & 0 \\
\hline Neuroticism & 0.028 & 0.000 & 25 & 0.031 & 0.000 & 27 & 0.028 & 0.000 & 25 \\
\hline
\end{tabular}

Presented are the Sobel test coefficient, $P$ value, and the proportion of the total effect that is mediated (\%). All variable coefficients are standardized. Variable definitions are in Table S2. To test for mediation we use the Sobel-Goodman method available in the Stata package that follows the logic described in Baron and Kenny (36). A variable is considered a mediator $(M)$ if it caries some part of the effect from an independent variable $(X)$, here positive affect and life satisfaction, onto a dependent variable $(Y)$, in our case later earnings. Mediation occurs if (i) $X$ significantly predicts $M$; (ii) $X$ significantly predicts $Y$ in the absence of $M$; (iii) $M$ significantly predicts $Y$ controlling for $X$; and (iv) the effect of $X$ on $Y$ shrinks upon addition of $M$. 
The paper's contribution is partly substantive and partly methodological. By the nature of its data, the study is able to introduce sibling fixed effects to account for much potential omitted-variable bias (family-related covariates, including a significant part of genetic endowment). Compared with individual fixed effects, sibling fixed effects allows for making inferences about the lagged effects of well-being at particular time points (such as adolescence and young adulthood) instead of having to consider variation between time intervals. This work also applies mediation analysis and may thus help to uncover the mechanisms running from well-being to later income. The most significant mediating pathways include obtaining a college degree, getting hired and promoted, and having higher degrees of optimism and extraversion and less neuroticism. Including current happiness in this longitudinal study allows us to better control for variation in latent well-being predisposition. This enables an examination of the consequences of variation in life satisfaction and positive affect at adolescence and young adulthood above and beyond any variation in the stable component of well-being. The use of a large US representative panel on this question also distinguishes this research from prior work that looked at the economic benefits of psychological well-being, as does offering a joint analysis of life satisfaction and positive affect. Finally, the study also attempts to account for a person's "anticipated happiness" in this kind of longitudinal analysis (through its use of proxy measures of current self-esteem). This should help to prevent a person's conscious or subconscious expectations about their future earnings from introducing bias into the estimate of the consequences of current psychological well-being.

For researchers who study human well-being, the message of the paper is that well-being regression equations cannot be expected to be estimated in a reliable way unless allowance is made for the endogeneity of income. This study also points to long time lags between psychological well-being in year $T$ and people's incomes in year $T+10$ and beyond. Greater knowledge of the underlying causes of these remarkable lags, and their reach in social and economic processes, will be needed. Research that considers the potential benefits of variation in life satisfaction or positive affect is part of a fairly new avenue in the study of human well-being. Although most research in this literature has studied the determinants of happiness, recently there has been growing interest in the broader benefits that happiness may induce $(10,29,37)$. For policymakers, the existence of these mechanisms raises the possibility that a happier society may be one that intrinsically generates higher incomes for its citizens. Traditional thinking has focused upon the opposite.

Although, in this paper, human well-being is considered instrumental or as a means-rather than an end in itself-it needs to be emphasized that this is not with a view to putting money center-stage at the expense of happiness. To the contrary, the results indicate that happiness and income are connected by a two-way relationship, and that human well-being can itself be a source of economic dynamism.

\section{Materials and Methods}

Data are from the restricted-use National Longitudinal Study of Adolescent Health (Add Health) sample available by contractual agreement (38). Add Health was started in 1994 to explore the health-related behavior of adolescents in grades 7-12. By now, four waves of data collection have taken place and participating subjects were around 30 y old in Wave IV (2008). The first wave of the Add Health study (1994-1995) selected 80 high schools from a sampling frame of 26,666 schools. The schools were selected based on their size, school type, census region, level of urbanization, and percent of the population that was white. Participating high schools were asked to identify junior high or middle schools that served as feeder schools to their school. This resulted in the participation of 145 middle, junior high, and high schools. From those schools, 90,118 students completed a 45-min questionnaire, and each school was asked to complete at least one School Administrator questionnaire. This process generated descriptive information about each student, the educational setting, and the environment of the school. From these respondents, a core random sample of adolescents in grades 7-12 were drawn plus several oversamples, bringing the total for Wave I to 20,745 adolescents. These students and their parents were administered inhome surveys. Wave II (1996) was comprised of another set of in-home interviews of 14,738 students from the Wave I sample. Wave III (2001-2002) consisted of an in-home interview of 15,197 Wave I participants. Finally, Wave IV (2008) consisted of an in-home interview of 15,701 Wave I participants. The result of this sampling design is that Add Health is a nationally representative study. Women make up $49 \%$ of the study's participants, Hispanics $12 \%$, Blacks $16 \%$, Asians 3\%, and Native Americans $2 \%$. Participants in Add Health also represent all regions of the US.

In Wave I of the Add Health study, researchers screened for sibling pairs including all adolescents that were identified as twin pairs, full siblings, half siblings, or unrelated siblings raised together. The sibling-pairs sample is similar in demographic composition to the full Add Health sample (35). Consequently, in all regression models we cluster the SEs of our estimates to better account for the fact that a subset of our observations is not independent. The structure of this data also allows us to compare siblings to each other while holding the family environment constant, which aids our interpretation of the relationship between well-being, childhood context, and income as an adult.

In all four interview waves of Add Health the subjects were asked about their subjective well-being. In particular, in waves I and II, the positive affect subscale of the Center for Epidemiologic Studies Depression Scale(CES-D) index (39) was administered. The CES-D index asks how often certain statements were true during the last week. The positive affect subscale is additively composed of the responses to the following four particular statements: "You enjoyed life," "You were happy," "You felt hopeful about the future," and "You felt that you were just as good as other people." The detailed question and answer structure for the four questions that make up this positive affect scale are given in Table S2. The life satisfaction question was surveyed in wave III only and asked: "How satisfied are you with your life as a whole?" Distribution tables for the positive affect and life satisfaction variables used in this research are presented in Tables S3-S6. Income in wave IV was reported as personal earnings before taxes and the mean income in the Add Health sample was approximately $\$ 35,000$. The measure for self-esteem was derived from the answer to "Compared with other people your age, how intelligent are you?" which was surveyed in all interview waves. Precise variable descriptions and descriptive statistics, as well as distribution scales for the well-being measures, are given in Table S2 for all variables used in this paper. A correlation matrix for the well-being measures across all interview waves and income in wave IV is also given in Table S1.

The analyses are run using linear regression models with clustering on SEs to better account for the fact that a subset of the Add Health observations are not independent. We also leverage the sibling clusters in the Add Health data by introducing family fixed effects (Table 2). The empirical framework here follows a standard specification where income (in 2008) is regressed on earlier subjective well-being measures and a set of other characteristics. With family fixed effects the empirical model takes the following form:

$$
Y_{\mathrm{ij}}=\beta_{0}+\beta_{1}\left(S W B_{\mathrm{ij}}\right)+\beta_{\mathrm{k}}\left(Z_{\mathrm{kij}}\right)+\mu_{\mathrm{j}}+\varepsilon_{\mathrm{ij}},
$$

where $i$ and $j$ index individual and family, respectively, and $Y_{\mathrm{ij}}$ is earnings. $Z_{\mathrm{k}}$ is a matrix comprised of variables that may differ between siblings (sex, age, height, self-esteem, etc.). To control for common family attributes, family fixed effects are introduced $\left(\mu_{\mathrm{j}}\right)$, and $\varepsilon_{\mathrm{ij}}$ represents an individual-specific error. Such family fixed-effect analyses are equivalent to differencing all equation variables within sibling pairs to account for family-related unobservables. For a discussion of assumptions involved see Griliches (40) and more recent surveys. Compared with individual fixed effect panel studies, the advantage of a family fixed effects model is that it allows for the study of longer-term effects of subjective well-being at a particular time period, here in adolescence and young adulthood

To test for mediation, we used the Sobel-Goodman method available in the STATA package that follows the logic described in Baron and Kenny (35). A variable is considered a mediator $(M)$ if it carries some part of the effect from an independent variable $(X)$, here positive affect and life satisfaction, onto a dependent variable $(Y)$, in our case later earnings. Mediation occurs if (i) $X$ significantly predicts $M$; (ii) $X$ significantly predicts $Y$ in the absence of $M$; (iii) $M$ significantly predicts $Y$ controlling for $X$; and (iv) the effect of $X$ on $Y$ shrinks upon addition of $M$. Description and references for the multivariate mediation test are provided in Table S9.

Information on how to obtain the Add Health data is available on the Add Health website (www.cpc.unc.edu/addhealth). 
ACKNOWLEDGMENTS. We thank Royal Economic Society Annual Conference participants (Cambridge University, 26-28 March 2012) and Richard Layard, Michael Norton, Steve Pischke, Alois Stutzer, Bert Van Landeghem, and Justin Wolfers for their helpful comments. All remaining errors are our own. Financial support from the UK Department for Work and Pensions and US National Institute on Aging (Grant R01AG040640) is gratefully

1. Kahneman D, Deaton A (2010) High income improves evaluation of life but not emotional well-being. Proc Natl Acad Sci USA 107(38):16489-16493.

2. Diener E, Biswas-Diener R (2002) Will money increase subjective well-being? Soc Indic Res 57:119-169.

3. Gardner J, Oswald AJ (2007) Money and mental wellbeing: A longitudinal study of medium-sized lottery wins. J Health Econ 26(1):49-60.

4. Dunn EW, Aknin LB, Norton MI (2008) Spending money on others promotes happiness. Science 319(5870):1687-1688.

5. Layard R, Mayraz G, Nickell S (2008) The marginal utility of income. J Public Econ 92: $1846-1857$.

6. Li H, Liu PW, Ye M, Zhang J (2011) Does money buy happiness? Evidence from twins in urban China (Tsinghua Univ, Beijing), Working Paper, available at: http://scholar. harvard.edu/maoliangye/publications/working-paper-"does-money-buy-happinessevidence-urban-china-using-twins"-ho.

7. Luttmer EFP (2005) Neighbors as negatives: Relative earnings and well-being. $Q J$ Econ 120(3):963-1002.

8. Clark AE, Oswald AJ (1996) Satisfaction and comparison income. J Public Econ 61:359-381.

9. Easterlin RA (2003) Explaining happiness. Proc Natl Acad Sci USA 100(19):11176-11183.

10. Frey BS (2011) Psychology. Happy people live longer. Science 331(6017):542-543.

11. Fowler JH, Christakis NA (2008) Dynamic spread of happiness in a large social network: longitudinal analysis over 20 years in the Framingham Heart Study. BMJ 337: a2338.

12. Lyubomirski S, Tkach C, DiMatteo MR (2006) What are the differences between happiness and self-esteem? Soc Indic Res 78:363-404.

13. Fredrickson BL, Branigan C (2005) Positive emotions broaden the scope of attention and thought-action repertoires. Cogn Emotion 19(3):313-332.

14. Schmitz TW, De Rosa E, Anderson AK (2009) Opposing influences of affective state valence on visual cortical encoding. J Neurosci 29(22):7199-7207.

15. Pessiglione M, Seymour B, Flandin G, Dolan RJ, Frith CD (2006) Dopamine-dependent prediction errors underpin reward-seeking behaviour in humans. Nature 442(7106): 1042-1045.

16. Wise RA (2004) Dopamine, learning and motivation. Nat Rev Neurosci 5(6):483-494.

17. Diener E, Nickerson C, Lucas RE, Sandvik E (2002) Dispositional affect and job outcomes. Soc Indic Res 59:229-259.

18. Shigehiro O, Diener E, Lucas R (2007) The optimum level of well-being: Can people be too happy? Perspect Psychol Sci 2(4):346-360.

19. Graham C, Eggers A, Sukhtankar S (2004) Does happiness pay? An exploration based on panel data from Russia. J Econ Behav Organ 55:319-342.

20. Binder M, Coad A (2010) An examination of the dynamics of well-being and life events using vector autoregressions. J Econ Behav Organ 76:352-371.

21. Guven C (2009) Reversing the question: Does happiness affect consumption and savings behavior? (German Socio-Economic Panel, Berlin), SOEPpapers on Multidisciplinary Panel Data Research No 219 acknowledged. This research uses data from Add Health, a program project directed by Kathleen Mullan Harris and designed by J. Richard Udry, Peter S. Bearman, and Kathleen Mullan Harris at the University of North Carolina at Chapel Hill, and funded by Grant P01-HD31921 from the Eunice Kennedy Shriver National Institute of Child Health and Human Development, with cooperative funding from 23 other federal agencies and foundations.

22. Oswald AJ, Proto E, Sgroi D (2009) Happiness and productivity (Institute for the Study of Labor, Bonn), IZA Discussion Paper No 4645.

23. Shawn A (2010) The Happiness Advantage (Random House, New York).

24. Lyubomirsky S, King L, Diener E (2005) The benefits of frequent positive affect: Does happiness lead to success? Psychol Bull 131(6):803-855.

25. Gilbert D (2006) Stumbling on Happiness (Knopf, New York).

26. Loewenstein $\mathrm{G}$ (1987) Anticipation and the valuation of delayed consumption. Econ 97:666-684.

27. Bartels M, Boomsma DI (2009) Born to be happy? The etiology of subjective wellbeing. Behav Genet 39(6):605-615.

28. Stone AA, Schwartz JE, Broderick JE, Deaton A (2010) A snapshot of the age distribution of psychological well-being in the United States. Proc Natl Acad Sci USA 107(22):9985-9990.

29. Steptoe A, Wardle J (2011) Positive affect measured using ecological momentary assessment and survival in older men and women. Proc Natl Acad Sci USA 108(45): $18244-18248$.

30. Waddell GR (2006) Labor-market consequences of poor attitude and low self-esteem in youth. Econ Inq 44(1):69-97.

31. Lykken DT, Tellegen A (1996) Happiness is a stochastic phenomenon. Psycho/ Sci 7(3): 186-189.

32. Weiss A, Bates TC, Luciano M (2008) Happiness is a personal(ity) thing: The genetics of personality and well-being in a representative sample. Psychol Sci 19(3):205-210.

33. De Neve J-E, Christakis NA, Fowler JH, Frey BS Genes, economics, and happiness. J Neuroscience Psychology Econ, 10.1037/a0030292.

34. De Neve J-E (2011) Functional polymorphism (5-HTTLPR) in the serotonin transporter gene is associated with subjective well-being: Evidence from a U.S. nationally representative sample. J Hum Gen 56(6):456-459.

35. Jacobson KC, Rowe DC (1998) Genetic and shared environmental influences on adolescent BMI: Interactions with race and sex. Behav Genet 28(4):265-278.

36. Baron RM, Kenny DA (1986) The moderator-mediator variable distinction in social psychological research: Conceptual, strategic, and statistical considerations. J Pers Soc Psychol 51(6):1173-1182.

37. Goudie RJB, Mukherjee S, De Neve J-E, Oswald AJ, Wu S (2012) Happiness as a driver of risk-avoiding behavior: A conceptual framework with an application to seatbelt wearing and automobile accidents Paper No CEP 1126 Centre for Economic Performance (CEP, London School of Economics).

38. Harris KM, et al. (2009) The national longitudinal study of adolescent health: Research design. Available at: www.cpc.unc.edu/projects/addhealth/design.

39. Radloff LS (1977) The CES-D scale: A self-report depression scale for research in the general population. Appl Psychol Meas 1(3):385-401.

40. Griliches $Z$ (1979) Sibling models and data in economics: Beginnings of a survey. J Polit Econ 78(5):S37-S64 